\section{Saúde bucal no Programa Saúde da Família: uma avaliação do modelo assistencial}

\author{
Oral health in the Brazilian Family Health Program: \\ a health care model evaluation
}

\author{
${ }^{1}$ Centro de Ciências da \\ Saúde, Universidade Federal \\ do Rio Grande do Norte, \\ Natal, Brasil. \\ Correspondência \\ T. M. S. Souza \\ Centro de Ciências da Saúde, \\ Universidade Federal do \\ Rio Grande do Norte. \\ Av. das Alagoas 1689, \\ Natal, RN \\ 59086-200, Brasil. \\ tatyanaufrn@hotmail.com
}

\section{Abstract}

The purpose of this study was to evaluate the addition of oral health teams to the Family Health Program in the State of Rio Grande do Norte, Brazil, by analyzing factors that can affect the process of changing oral health care models. The evaluation involved three dimensions: access, work organization, and planning strategies. 19 counties (municipalities) were randomly selected. The data collection instruments were: structured interviews with health managers and dentists, structured observation, and documental research. The study identified a lack of formal employment contracts for dentists, difficulty in referring patients for high-complexity procedures, and problems with the development of inter-sector activities, epidemiological diagnoses, and work evaluation. Most of the counties showed little or no improvement in oral health care. The counties that had improved their oral health care were the same ones with higher life expectancy, lower infant mortality rates, higher per capita income, and higher human development index (HDI). In conclusion, public policies that include aspects beyond the health sector are decisive for a real change in health care models.

Oral Health; Family Health Program; Health Services
Tatyana Maria Silva de Souza ${ }^{1}$

Angelo Giuseppe Roncalli 1

\section{Introdução}

O Programa Saúde da Família (PSF) tem se tornado, nos últimos anos, o principal programa alavancador da reorganização dos serviços de saúde na atenção básica. Tem como estratégia a reformulação do processo de trabalho inserido no contexto do Sistema Único de Saúde (SUS) e centrado na vigilância à saúde por meio de ações de promoção, prevenção e recuperação; baseia-se na nova concepção sobre o processo saúde-doença, com atenção voltada para a família e com ações organizadas em um território definido. Tornou-se o carro-chefe do modelo assistencial do SUS e foi concebido pelo Ministério da Saúde como uma alternativa de promover a reformulação das ações em saúde, considerando que o modelo tradicional de assistência impôs um descompasso entre os princípios do SUS e a realidade concreta de implantação do sistema de saúde 1,2,3.

Entendendo a saúde bucal como integrante desse processo, a sua incorporação ao PSF tem sido vista como possibilidade de romper com os modelos assistenciais em saúde bucal excludentes baseados no curativismo, tecnicismo e biologicismo. Isso porque o PSF, de certa forma, tenta romper com a lógica programática desses modelos, visto que não só articula as propostas da vigilância à saúde baseando-se na integralidade, mas também possui como um de seus princípios a busca ativa de famílias, 
as quais são consideradas como núcleo social primário.

A incorporação oficial do cirurgião-dentista na equipe de saúde da família aconteceu somente em 2000 dentro de um contexto político, econômico e social favorável. O Ministério da Saúde estabeleceu, por meio da Portaria $n^{\circ}$. 1.444, o incentivo financeiro à inclusão das equipes de saúde bucal no PSF 4, o que resultou em um grande impulso de sua expansão pelo Brasil.

Segundo Calado 5, antes da inclusão oficial da saúde bucal no PSF, havia relatos de 76 experiências de incorporação do cirurgião-dentista nas equipes de saúde da família no país. Num intervalo de apenas dois anos após a divulgação da Portaria de incentivos, em fevereiro de 2002, segundo o Ministério da Saúde ${ }^{6}$, o número de municípios com equipe de saúde bucal aumentou substancialmente para 1.526 em todo o Brasil. Em janeiro de 2006, esse número era de 12.847 (http://www.datasus.gov.br, acessado em Mar/2004).

O aumento do incentivo financeiro, concedido pelo Ministério da Saúde, para a saúde bucal no PSF nesses últimos anos é reflexo da sua relevância no novo momento político do Brasil. A atual Política Nacional de Saúde Bucal tem como um de seus pressupostos, do ponto de vista assistencial, a operacionalização da oferta de serviços na atenção básica através do PSF. Ainda com relação à assistência, a política incentiva o aumento da oferta de procedimentos nos níveis secundário e terciário da atenção com a implantação de Centros de Especialidades Odontológicas, que são unidades de referência para as equipes de saúde bucal (http://www.portal.saude.gov.br, acessado em Fev/2006).

Mesmo com a promessa de reorganização das ações na atenção básica pautadas numa nova concepção do processo saúde-doença e mesmo com sua rápida expansão por todo o país, impulsionada pelo próprio Ministério da Saúde, isso não implica, necessariamente, uma mudança do modelo assistencial em saúde bucal. Segundo Zanetti 7, caso o incentivo financeiro seja visto como "atraente" pelos prefeitos, esse crescimento "exponencial" das equipes de saúde bucal pelo Brasil será "desorganizado", "pautado no ensaísmo programático", "constituindo um crescimento 'tumoral' e não 'orgânico' ao sistema". Além disso, caso a implantação da equipe de saúde bucal no PSF se torne, na prática, a tradução das políticas de racionalização de saúde que são incentivadas pelas instituições internacionais, como o Banco Mundial, estaremos reproduzindo, também na saúde bucal, um modelo programático focal e excludente.

Algumas características inerentes à própria profissão conferem à saúde bucal particularida- des que dificultam sua prática no setor público como, por exemplo, a necessidade do uso de tecnologias duras na atenção básica.

Outro ponto crítico diz respeito aos recursos humanos na saúde bucal. A integração da equipe de saúde bucal com a de saúde da família para a realização de um trabalho em conjunto tem sido um dos maiores desafios para a saúde bucal. Moysés \& Silveira Filho 8 acreditam que a inclusão de equipes multiprofissionais no processo de assistência ou do cuidado possibilita organizar o trabalho com níveis de complementaridade e, ao mesmo tempo, de especificidade, ou seja, há que se complementarem os campos de saberes das profissões sem excluir a especificidade de cada uma. Ainda relativo aos recursos humanos, no que diz respeito às relações de trabalho do profissional com o município, o que tem acontecido é a contratação, sem critério algum, de profissionais, propiciando práticas clientelistas e vínculos contratuais ilegais, ou até mesmo inexistentes em alguns casos 9 .

Portanto, diante da expressividade com que a incorporação da equipe de saúde bucal no PSF tem se expandido por todo o país; pelo fato de o programa ter se tornado, especialmente na saúde bucal, a principal (em alguns casos a única) maneira de organização dos recursos físicos, humanos, tecnológicos para responder às necessidades de saúde bucal da população; pela possibilidade de reorganizar as ações em saúde bucal a partir da concepção ampla do processo saúde-doença, baseado na promoção, prevenção e assistência à saúde, e pela necessidade de avaliação das ações desenvolvidas pelas equipes de saúde bucal no PSF no Rio Grande do Norte, o qual tem sua realidade semelhante à de outros estados do Nordeste, este estudo tem como objetivo avaliar a incorporação da saúde bucal no PSF, com base na análise de fatores que interferem positiva ou negativamente na implementação dessa estratégia e, conseqüentemente, no processo de mudança dos modelos assistenciais em saúde bucal no SUS no Estado do Rio Grande do Norte, Brasil.

\section{Metodologia}

O presente estudo foi desenvolvido no Estado do Rio Grande do Norte no ano de 2004. Os municípios participantes da pesquisa deveriam ter pelo menos uma equipe de saúde bucal no PSF com, no mínimo, um ano de implantação, por se considerar que, para a constatação da mudança do modelo assistencial, seria necessário esse tempo de implantação. As mudanças em um modelo assistencial, como se sabe, dependem, dentre outros fatores, do contexto político, da organização 
dos serviços, de processos de capacitação e do envolvimento da equipe.

Para a seleção dos municípios participantes, tomou-se como base a amostra do Projeto SB Brasil-RN 10, primeiro levantamento epidemiológico das condições de saúde bucal do Rio Grande do Norte, desenvolvido pela Secretaria de Estado de Saúde Pública do Rio Grande do Norte (SESAP/RN). A escolha dessa amostra se deu pelo seu caráter probabilístico e por sua distribuição pelas sete Unidades Regionais de Saúde Pública do Estado, o que lhe confere uma boa distribuição geográfica.

Dos 38 municípios sorteados para o Projeto SB Brasil-RN, foram selecionadas para a composição da amostra do presente estudo vinte unidades amostrais, por questões operacionais e por este número permitir uma dispersão razoável dos dados coletados 11 .

Essas unidades foram estratificadas, com base em seu Índice de Desenvolvimento Humano Municipal (IDH-M) de 2000, em municípios de baixo, médio ou alto IDH-M, considerando-se sua distribuição percentil. Tal classificação permitiu seu uso posterior como variável independente de caráter sócio-econômico. Deve-se considerar que o fato de terem sido utilizados dados deste índice relativos ao ano 2000 em uma pes- quisa cuja coleta de dados se refere a 2004 pode constituir uma limitação. Entretanto, o IDH-M serviu, neste caso, como medida de estratificação, de modo que, embora os valores do índice possam ter mudado ao longo de quatro anos, tais mudanças pouco alteraram as posições dos municípios estudados em termos comparativos.

Os municípios selecionados para o presente estudo encontram-se na Figura 1, distribuídos por Unidades Regionais de Saúde Pública e categorizados quanto ao IDH-M. O Município de Natal corresponde a duas frações da amostra, por possuir a maior população do Estado.

Quanto ao porte populacional, a amostra foi composta por cinco municípios com até $10 \mathrm{mil}$ habitantes, cinco municípios com população entre 10 mil e 20 mil habitantes, cinco municípios com população entre 20 mil e 50 mil habitantes e quatro municípios com mais de 50 mil habitantes. A amostra conta com municípios de vários portes populacionais, o que lhe confere uma característica de maior representatividade no Rio Grande do Norte, uma vez que essa proporção é a mesma para a população total do Estado. Tal proporcionalidade foi estabelecida a partir de um sorteio ponderado, tendo a população total de cada município funcionado como fator de ponderação.

Figura 1

Municípios da pesquisa segundo o Índice de Desenvolvimento Humano Municipal (IDH-M) e região administrativa de saúde. Rio Grande do Norte, Brasil, 2004.

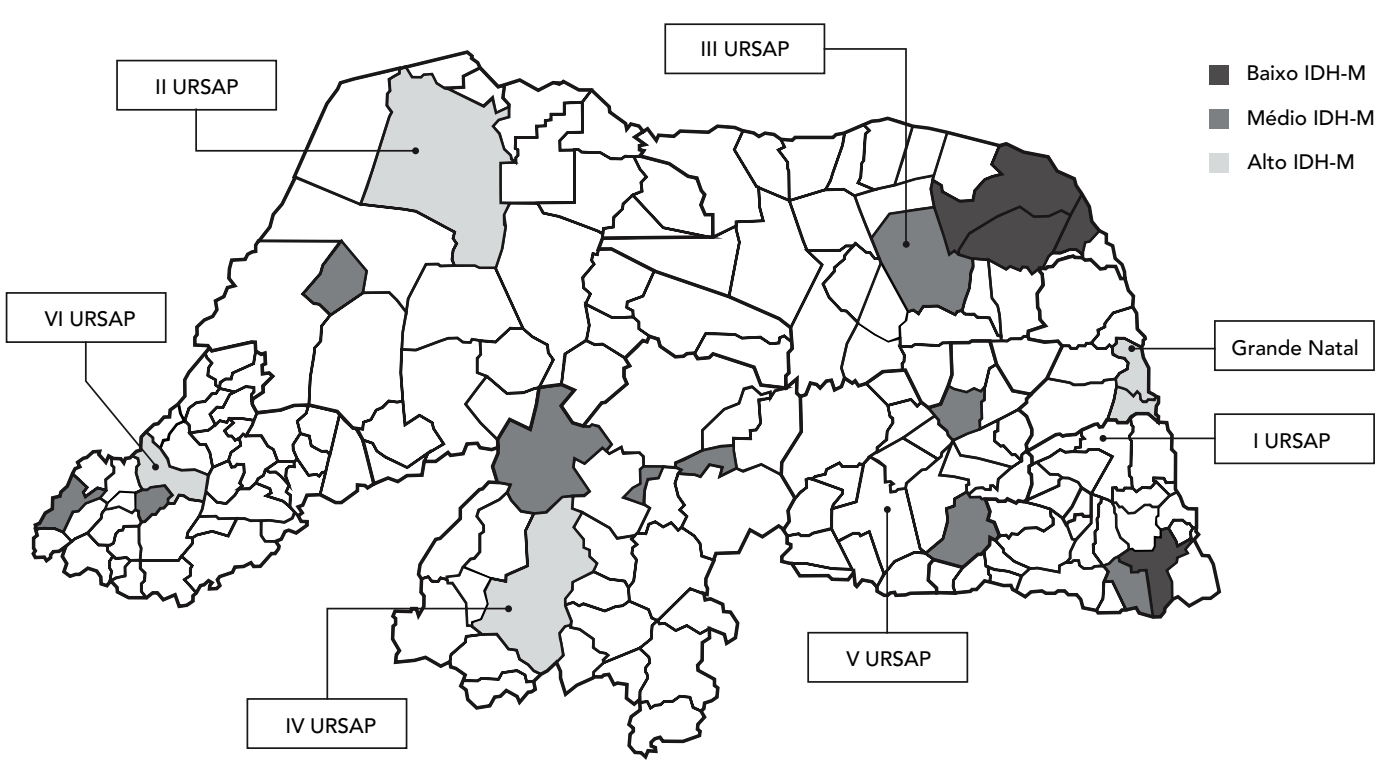

URSAP: Unidade Regional de Saúde Pública. 
Foram realizadas entrevistas estruturadas mediante a aplicação de questionários com perguntas abertas e fechadas aos gestores (coordenadores ou responsáveis pela Saúde Bucal) e dentistas das equipes de saúde bucal dos municípios. Foram entrevistados 19 coordenadores ou responsáveis pela saúde bucal e 25 dentistas, totalizando 44 sujeitos participantes.

Além das entrevistas, realizou-se pesquisa documental (documentos referentes à saúde bucal, tais como relatórios de ações desenvolvidas, projetos desenvolvidos, fichas clínicas utilizadas pelo município e protocolos de atendimento em saúde bucal) e observação estruturada durante a visita às unidades de saúde da família, a fim de verificar a capacidade instalada da equipe de saúde bucal na unidade, bem como equipamentos, instrumental e materiais de consumo disponíveis para a equipe de saúde bucal.

Os resultados da análise documental, da observação estruturada e dos questionários foram agrupados em uma matriz avaliativa a partir de processos de pós-categorização. A avaliação da intervenção, que consiste na incorporação da saúde bucal no PSF, foi realizada a partir de três dimensões: organização do trabalho na equipe de saúde bucal, acesso da população aos serviços de saúde bucal e estratégias de programação desenvolvidas pela equipe.

Na dimensão do acesso, abordamos aspectos relacionados às estratégias de territorialização, à cobertura e ao sistema de referência e contra-referência. Na dimensão da organização do trabalho, abordamos a questão do trabalho em equipe e a intersetorialidade. Na dimensão das estratégias de programação, concentramo-nos na realização de diagnósticos epidemiológicos, de avaliações das ações individuais e coletivas.
Os resultados foram categorizados e inseridos em uma matriz avaliativa (Tabela 2). Através dessa matriz, tentamos estabelecer, para cada município da amostra, uma classificação da incorporação da saúde bucal no PSF, a partir das categorias insatisfatória (I), pouco satisfatória (PS) ou satisfatória (S), de acordo com critérios pré-estabelecidos (Tabela 1). Ao final, observamos qual classificação foi mais expressiva dentre as categorias. Por exemplo, o município que apresentou a maioria das variáveis classificada como satisfatória teve uma classificação final "satisfatória" de incorporação da saúde bucal no PSF (Tabela 2).

Além dos resultados das dimensões abordadas, incorporamos à matriz alguns indicadores sócio-econômicos dos municípios e as suas respectivas populações. Esses indicadores também foram categorizados como alto, médio e baixo, a fim de correlacionarem-se com a tendência observada no município. Vale salientar que essas variáveis não interferiram na classificação final; fizeram parte de uma análise posterior, em que se correlacionou a classificação final com tais indicadores em cada município.

Nos casos em que duas classificações tiveram a mesma proporção utilizamos, como critério para a opção por uma delas, uma avaliação de caráter qualitativo, escolhendo a subcategoria com maior poder de impactar na mudança do modelo. A título de exemplo, a intersetorialidade, que demonstra a inter-relação da saúde com outros setores a fim de melhorar a qualidade de vida da população, foi considerada como categoria avaliativa preponderante em um eventual empate.

O presente estudo obedece aos princípios éticos contidos na Declaração de Helsinki e foi aprovado pelo Comitê de Ética da Universidade

Tabela 1

Descrição das classificações insatisfatória, pouco satisfatória e satisfatória, de acordo com as categorias e subcategorias

\begin{tabular}{|c|c|c|c|c|}
\hline Categoria & Descrição & Insatisfatória & Pouco satisfatória & Satisfatória \\
\hline Relações de trabalho & $\begin{array}{c}\text { Salário * + vínculo } \\
\text { contratual + forma de } \\
\text { contratação + jornada } \\
\text { de trabalho }\end{array}$ & $\begin{array}{l}\text { 1. Salário insatisfatório + } \\
\text { temporário + indicado } \\
\text { + sem contrato para } \\
\text { 40h ou não cumpre } \\
\text { 40h ou cumpre } 40 h \\
\text { 2. Salário pouco satisfatório } \\
\text { + temporário + indicado } \\
\text { + não cumpre } 40 \mathrm{~h}\end{array}$ & $\begin{array}{l}\text { 1. Salário pouco satisfatório } \\
\text { ou satisfatório + temporário } \\
\text { + indicado + cumpre } 40 \mathrm{~h} \\
\text { 2. Salário pouco satisfatório } \\
\text { ou satisfatório + CLT } \\
\text { ou estatutário + indicado } \\
\text { ou selecionado + sem } \\
\text { contrato para } 40 \mathrm{~h} \text { ou não } \\
\text { cumpre } 40 \mathrm{~h} \text { ou cumpre } 40 \mathrm{~h}\end{array}$ & $\begin{array}{l}\text { 1. Salário satisfatório + } \\
\text { CLT ou estatutário + } \\
\text { selecionado + cumpre } 40 \mathrm{~h}\end{array}$ \\
\hline
\end{tabular}

(continua) 
Tabela 1 (continuação)

\begin{tabular}{|c|c|c|c|c|}
\hline Categoria & Descrição & Insatisfatória & Pouco satisfatória & Satisfatória \\
\hline \multirow[t]{3}{*}{ Acesso } & $\begin{array}{l}\text { Estratégias de } \\
\text { territorialização }\end{array}$ & $\begin{array}{l}\text { Não apresenta estratégias } \\
\text { de territorialização e adscrição } \\
\text { nem mapeamento da área }\end{array}$ & $\begin{array}{l}\text { Apresenta estratégias de } \\
\text { territorialização e adscrição, } \\
\text { porém não tem } \\
\text { mapeamento da área }\end{array}$ & $\begin{array}{l}\text { Apresenta estratégias de } \\
\text { territorialização e adscrição } \\
\text { e mapeamento da área }\end{array}$ \\
\hline & Cobertura ** & $16 \% \mid--41,78 \%$ & $41,78 \% \mid--67,6 \%$ & $67,6 \%|--| 100 \%$ \\
\hline & $\begin{array}{l}\text { Sistema de referência e } \\
\text { contra-referência }\end{array}$ & $\begin{array}{l}\text { O sistema de referência e } \\
\text { contra-referência não funciona, } \\
\text { segundo dentistas e gestores }\end{array}$ & $\begin{array}{l}\text { O sistema de referência e } \\
\text { contra-referência funciona } \\
\text { precariamente, segundo } \\
\text { gestores e dentistas, ou há } \\
\text { discordância sobre o funciona- } \\
\text { mento do sistema de referência } \\
\text { e contra-referência entre os } \\
\text { dentistas e os gestores } \\
\text { ** }\end{array}$ & $\begin{array}{l}\text { O sistema de referência e } \\
\text { contra-referência funciona } \\
\text { adequadamente, segundo } \\
\text { gestores e dentistas }\end{array}$ \\
\hline \multirow[t]{3}{*}{$\begin{array}{l}\text { Organização } \\
\text { do trabalho }\end{array}$} & Reunião em equipe & $\begin{array}{c}\text { Não há reuniões em equipe } \\
\text { ou não participa delas }\end{array}$ & $\begin{array}{l}\text { Participa esporadicamente } \\
\text { das reuniões em equipe }\end{array}$ & $\begin{array}{l}\text { Sempre participa das } \\
\text { reuniões em equipe }\end{array}$ \\
\hline & Ações em equipe & $\begin{array}{c}\text { Não desenvolve ações } \\
\text { em equipe }\end{array}$ & $\begin{array}{c}\text { Desenvolve esporadicamente } \\
\text { ações em equipe }\end{array}$ & $\begin{array}{l}\text { Sempre desenvolve } \\
\text { ações em equipe }\end{array}$ \\
\hline & Intersetorialidade & $\begin{array}{c}\text { Não há ações intersetoriais } \\
\text { ou relata ações que não } \\
\text { correspondem a ações } \\
\text { intersetoriais }\end{array}$ & $\begin{array}{l}\text { Relata ações que, embora } \\
\text { ocorram em outros espaços } \\
\text { (que não a unidade), não } \\
\text { possuem articulação intersetorial }\end{array}$ & $\begin{array}{l}\text { Existe articulação com } \\
\text { outras secretarias }\end{array}$ \\
\hline \multirow[t]{4}{*}{$\begin{array}{l}\text { Estratégias de } \\
\text { programação }\end{array}$} & $\begin{array}{l}\text { Diagnóstico } \\
\text { epidemiológico }\end{array}$ & $\begin{array}{l}\text { Não realizado pelo } \\
\text { município }\end{array}$ & $\begin{array}{l}\text { Realizado pelo município, } \\
\text { porém não utilizado pelo } \\
\text { dentista ou realizado } \\
\text { somente pelo dentista }\end{array}$ & $\begin{array}{l}\text { Realizado pelo município e } \\
\text { utilizado pelo dentista }\end{array}$ \\
\hline & Ações individuais & $\begin{array}{l}\text { Não realiza ações individuais } \\
\text { ou só faz exodontias }\end{array}$ & & $\begin{array}{l}\text { Realiza procedimentos } \\
\text { restauradores e preventivos }\end{array}$ \\
\hline & Ações coletivas & Não realiza & & Realiza \\
\hline & Avaliação & Não realiza avaliação & $\begin{array}{c}\text { Avaliação realizada } \\
\text { somente pelo gestor ou } \\
\text { somente pelo dentista }\end{array}$ & $\begin{array}{l}\text { Avaliação realizada pelos } \\
\text { gestores e dentistas }\end{array}$ \\
\hline Documentação & $\begin{array}{l}\text { Documentos de registro, } \\
\text { relatórios, projetos, } \\
\text { protocolos de atendimento }\end{array}$ & $\begin{array}{l}\text { Não há qualquer tipo } \\
\text { de documento }\end{array}$ & $\begin{array}{l}\text { Há documentos de registro } \\
\text { ou relatórios ou projetos }\end{array}$ & $\begin{array}{c}\text { Há documentos de registros } \\
\text { ou protocolos de } \\
\text { atendimento }\end{array}$ \\
\hline $\begin{array}{l}\text { Infra-estrutura } \\
\text { observada }\end{array}$ & $\begin{array}{c}\text { Estrutura física, instrumentos, } \\
\text { equipamentos }\end{array}$ & $\begin{array}{c}\text { Não houve atendimento } \\
\text { durante a observação, } \\
\text { falta de estrutura física, } \\
\text { instrumental clínico insuficiente } \\
\text { ou inexistente, } \\
\text { equipamentos velhos e/ou } \\
\text { desativados ou inexistentes }\end{array}$ & $\begin{array}{c}\text { Dificuldade de esterilização } \\
\text { do instrumental, problemas } \\
\text { na estrutura física, consultórios } \\
\text { bem equipados, instrumental } \\
\text { clínico suficiente, espaço para } \\
\text { atividades educativas }\end{array}$ & $\begin{array}{l}\text { Consultórios odontológicos } \\
\text { bem equipados, espaços } \\
\text { humanizados, unidades de } \\
\text { saúde com espaço para } \\
\text { atividades educativas, central } \\
\text { de marcação de consultas }\end{array}$ \\
\hline
\end{tabular}

CLT: Consolidação das Leis do Trabalho.

* Intervalos para categorização dos salários. Insatisfatório: 500,00 |- 1.324,00; Pouco satisfatório: 1.324,00 |-- 2.800,00; Satisfatório: 2.800,00 |--| 3.272,00.

Categorização levando em consideração os quartis 25 e 75 dos valores encontrados na amostra;

** Intervalos estabelecidos de acordo com os percentis 33 e 66 de acordo com os valores encontrados na amostra;

*** Foram considerados discordantes os casos em que, por exemplo, o gestor afirma que o sistema de referência e contra-referência funciona adequadamente, ao passo que o dentista afirma que o sistema não existe. 
Matriz avaliativa, contendo as variáveis estudadas relativas às características dos municípios e os indicadores do modelo assistencial. Rio Grande do Norte, Brasil, 2004.

\begin{tabular}{|c|c|c|c|c|c|c|c|c|c|c|c|c|c|c|c|c|c|c|c|c|}
\hline \multirow[t]{4}{*}{$M$} & \multirow[t]{4}{*}{ Pop } & \multirow[t]{4}{*}{ Pop\% } & \multirow[t]{4}{*}{ IDH } & \multirow[t]{4}{*}{ MI } & \multirow[t]{4}{*}{ An } & \multirow[t]{4}{*}{ IP } & \multicolumn{10}{|c|}{ Dimensões } & \multirow[t]{4}{*}{ RT } & \multirow[t]{4}{*}{ Doc } & \multirow[t]{4}{*}{ Estr } & \multirow[t]{4}{*}{ CF } \\
\hline & & & & & & & \multirow{2}{*}{\multicolumn{3}{|c|}{ Acesso }} & \multirow{2}{*}{\multicolumn{3}{|c|}{$\begin{array}{l}\text { Organização } \\
\text { do Trabalho }\end{array}$}} & & \multirow{2}{*}{\multicolumn{3}{|c|}{$\begin{array}{l}\text { Estratégia de } \\
\text { Programação }\end{array}$}} & & & & \\
\hline & & & & & & & & & & & & & & & & & & & & \\
\hline & & & & & & & ET & $\mathrm{C}$ & SRCR $^{2}$ & Reun & Ações & Inter & $\mathrm{Al}$ & $A C$ & DE & Av & & & & \\
\hline
\end{tabular}

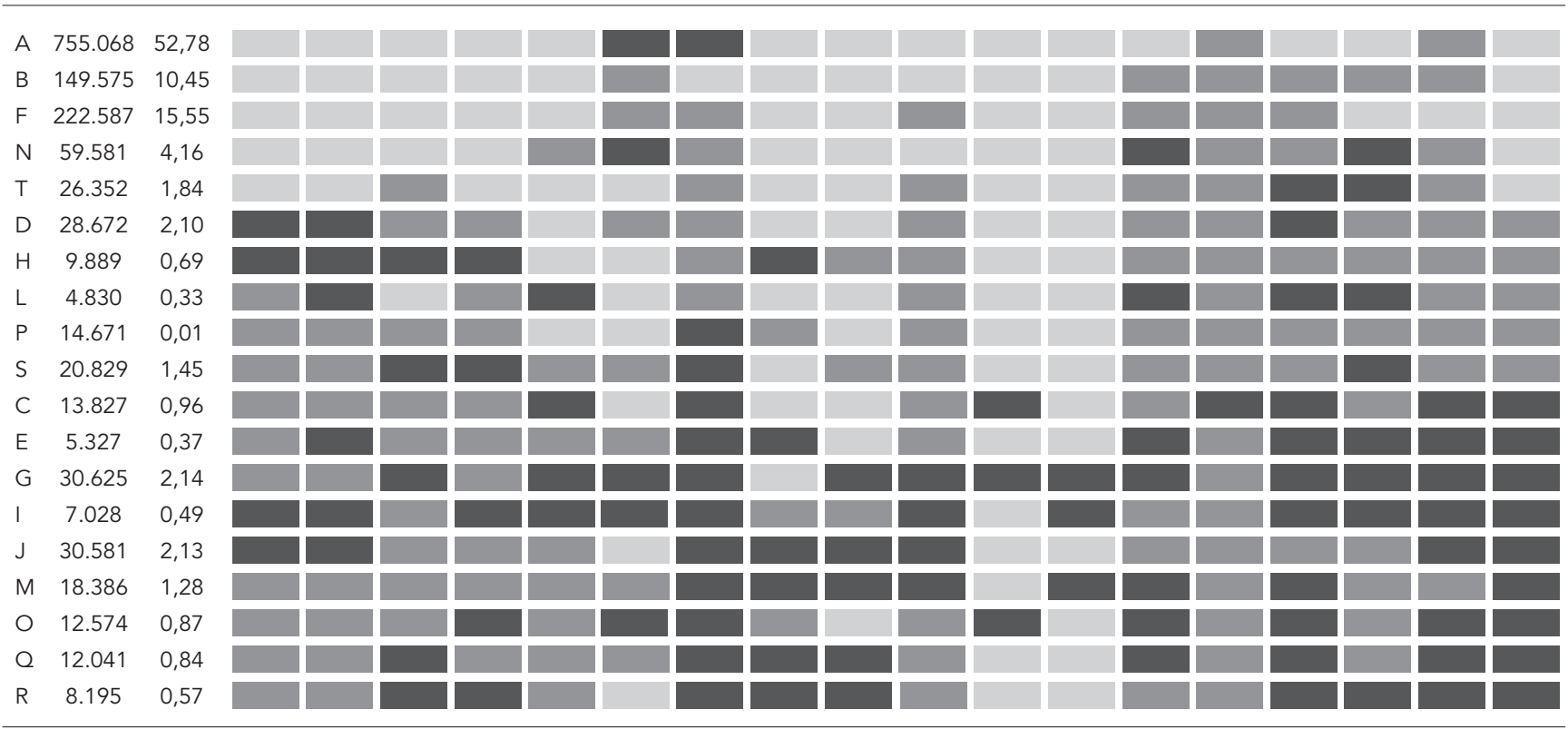

Legenda: M: município; Pop: população; Pop\%: proporção da população do município em relação à população total da amostra; IDH: Índice de Desenvolvimento Humano; MI: mortalidade infantil; An: percentual de analfabetismo em crianças de 7-14 anos; IP: intensidade de pobreza; ET: estratégias de territorialização; C: cobertura; SRCR: sistema de referência e contra-referência; Reun: reuniões em equipe; ações: ações em equipe; Inter: intersetorialidade; Al: ações individuais; AC: ações coletivas; DE: diagnósticos epidemiológicos; Av: avaliação; RT: relações de trabalho; Doc: documentação; Estr: estrutura observada; CF: classificação final.

\begin{tabular}{|l|l|}
\hline Satisfatório \\
\hline Pouco satisfatório \\
Insatisfatório
\end{tabular}

Federal do Rio Grande do Norte. Está registrado sob o número 50/04 e teve sua aprovação em 04 de junho de 2004.

\section{Resultados e discussão}

\section{As relações de trabalho dos profissionais com os municípios}

A precarização das relações de trabalho foi evidenciada quando constatamos que um grande número de dentistas (40\%) tem com o município uma relação firmada através de contratos temporários, o que acarreta instabilidade no emprego. Além disso, a forma de contratação de $40 \%$ dos dentistas foi por indicação, ou seja, não houve qualquer seleção para esses profissionais, fato que pode levar às conhecidas práticas clientelistas.

O monitoramento da implantação e funcionamento das equipes de saúde da família no Brasil 12 realizado pelo Ministério da Saúde no Estado também abordou a questão do vínculo contratual dos dentistas nos municípios. Da mesma forma que no nosso estudo, foi constatado um alto percentual de contratos temporários ou contratos informais $(47,4 \%)$. Somente $3,3 \%$ eram vinculados através do regime da Consolidação das Leis de Trabalho e 27,6\% eram estatutários.

Ainda nessa discussão, Carvalho \& Girardi 9 também verificaram, em uma pesquisa de âmbito nacional, que as contratações são realizadas 
na maior parte dos municípios pelas prefeituras municipais, sendo contratos temporários ou prestação de serviços a principal forma de contratar os profissionais da equipe saúde da família e equipe de saúde bucal, o que enfraquece o vínculo do profissional. Na metade dos municípios, a forma de contratação precária se estende a outros setores da prefeitura além do setor saúde. A flexibilização foi o primeiro motivo citado pelos municípios para a adoção de formas precárias de contratação de profissionais. Infelizmente, na prática, essa flexibilização, considerada por Viana \& Dal Poz ${ }^{3}$ como "elementos de reforço ao processo de mudança”, tem sido traduzida em instabilidade no emprego e em práticas clientelistas, especialmente nos municípios de menor porte (com até 100 mil habitantes) ${ }^{9}$.

Contradições são observadas ao confrontarmos dados a respeito da jornada de trabalho contratada e da jornada de trabalho cumprida. Observou-se que $80 \%$ dos dentistas têm contrato de 40 horas semanais de trabalho, e $40 \%$ destes não cumprem a carga horária. Dentre os que afirmam cumprir as 40 horas semanais, mais da metade mora no município no qual está trabalhando.

Os dados do monitoramento também confirmam a dificuldade do cumprimento da carga horária por parte dos dentistas. Apesar de 89,5\% terem um contrato de 40 horas semanais, somente $48,7 \%$ afirmavam cumprir o horário 12 .

Provavelmente, além da questão da residência fixa no município, a questão salarial pode estar interferindo no cumprimento da carga horária, o que, por sua vez, interfere no estabelecimento de vínculo com a comunidade, no desenvolvimento de atividades de promoção, prevenção e reabilitação em saúde. Analisando os dados relativos à remuneração dos dentistas, constatou-se que $25 \%$ deles recebem menos de $\mathrm{R} \$ 1.324,00 ; 50 \%$ recebem menos de $\mathrm{R} \$ 1.800,00$; $25 \%$ recebem entre $\mathrm{R} \$ 1.800,00$ e $\mathrm{R} \$ 2.800,00$ e apenas $25 \%$ recebem acima de $\mathrm{R} \$ 2.800,00$. Relacionando-se o cumprimento da carga horária com a remuneração, observou-se que, dentre os 13 dentistas que não cumprem a carga horária de 40 horas semanais, sete ganham um salário menor ou igual a $\mathrm{R} \$ 1.800,00$.

É possível perceber, portanto, com base nos dados encontrados no nosso estudo, bem como nos de outras pesquisas supracitadas, que as relações de trabalho dos profissionais do PSF são precárias, o que é evidenciado por alguns aspectos como: (a) a forma de incorporação, muitas vezes sem critérios ou concursos, o que favorece as práticas clientelistas; (b) as formas de contratação informais e precárias, provocando instabilidade no emprego; (c) a questão salarial, não havendo isonomia e sendo baixa a remuneração dos dentistas; (d) a jornada de trabalho semanal de 40 horas, que, por muitos motivos, incluindo a residência fixa e os salários, não tem sido cumprida. Esses fatores na sua inter-relação, mesmo não sendo determinantes no modo como se define a assistência ao usuário do serviço, podem estar interferindo nessa questão.

\section{Acesso da população aos serviços de saúde bucal}

Quatro municípios não apresentavam estratégias de territorialização e adscrição de clientela (área de abrangência definida), nem o mapeamento da área (indicando as micro-áreas e as áreas de risco, por exemplo). Os demais municípios dividiam-se do seguinte modo: sete apresentavam área de abrangência e mapeamento da área; oito, apesar de terem área de abrangência, não tinham o mapeamento (Tabela 2).

Com relação à atenção secundária e terciária em saúde bucal, de acordo com seis gestores $(31,6 \%)$, o sistema de referência e contra-referência existe no próprio município; nove (47,3\%) afirmam que há pactuação com outro município para a realização da referência e contra-referência em saúde bucal e quatro (21\%) afirmam que não há referenciamento dos pacientes. Dos seis gestores que declaram existir referenciamento no próprio município, quatro afirmam que o sistema não funciona ou funciona precariamente. Dos nove gestores que afirmam que há pactuação com outro município, sete consideram que o referenciamento não funciona, ou funciona precariamente (Figura 2). As principais dificuldades citadas para que o sistema de referência e contrareferência não funcione dizem respeito à falta de recursos humanos capacitados para atividades de média complexidade $(36,8 \%)$ e à falta de centros de referência em saúde bucal $(31,6 \%)$.

Entre os dentistas, por sua vez, a opinião de que o sistema de referência e contra-referência não é adequado é quase unânime. Dos 25 dentistas, 14 afirmam que não existe referenciamento dos pacientes e oito dizem que este existe, porém não funciona ou funciona de maneira irregular e insatisfatória. Apenas três consideraram adequado o sistema de referência e contra-referência existente (Figura 3). Interessante observar que, dos três municípios onde os gestores asseguraram ser o sistema adequado, em dois os dentistas afirmaram que o referenciamento não existe e em apenas um houve concordância entre gestor e dentista quanto à eficiência do sistema.

No que diz respeito à cobertura, observa-se, através da matriz avaliativa, que os sete municípios que apresentaram uma cobertura populacional 
Sistema de referência e contra-referência, segundo os gestores. Rio Grande do Norte, Brasil, 2004.

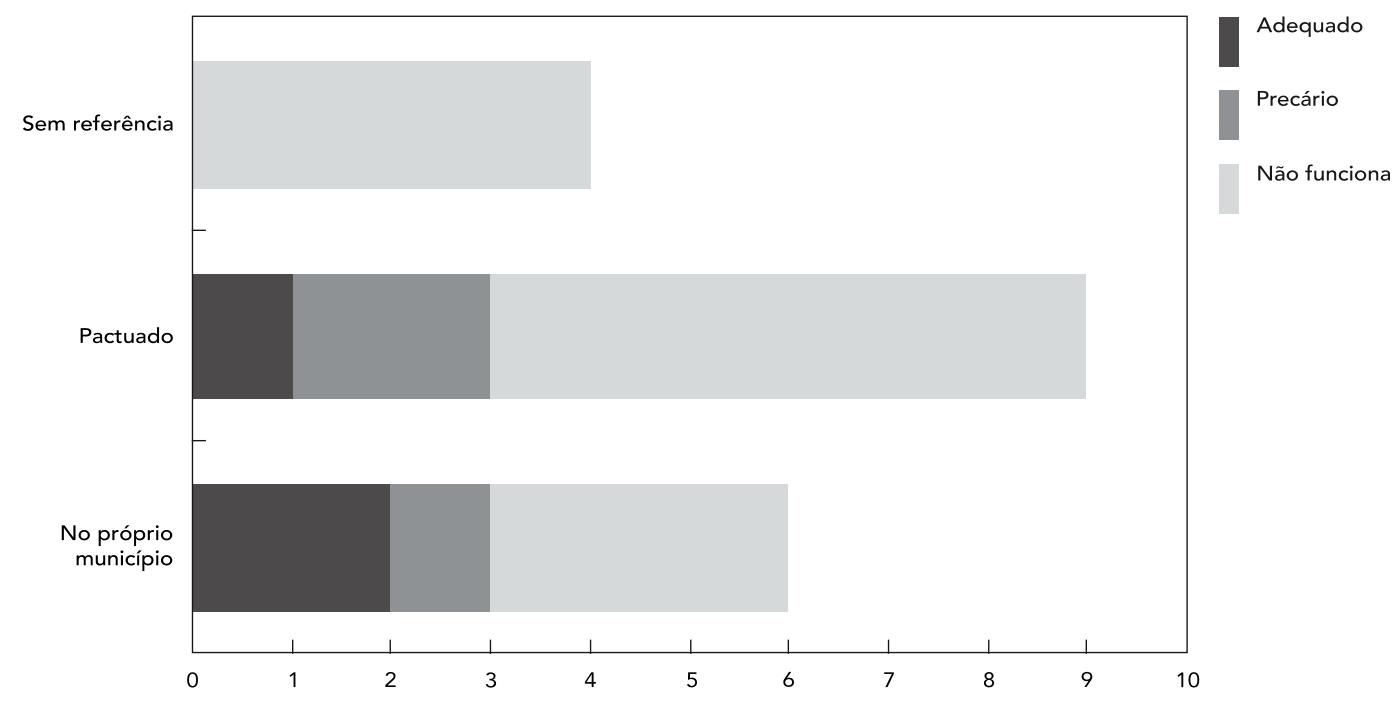

Figura 3

Avaliação da qualidade do sistema de referência e contra-referência em saúde bucal, segundo os dentistas. Rio Grande do Norte, Brasil, 2004.

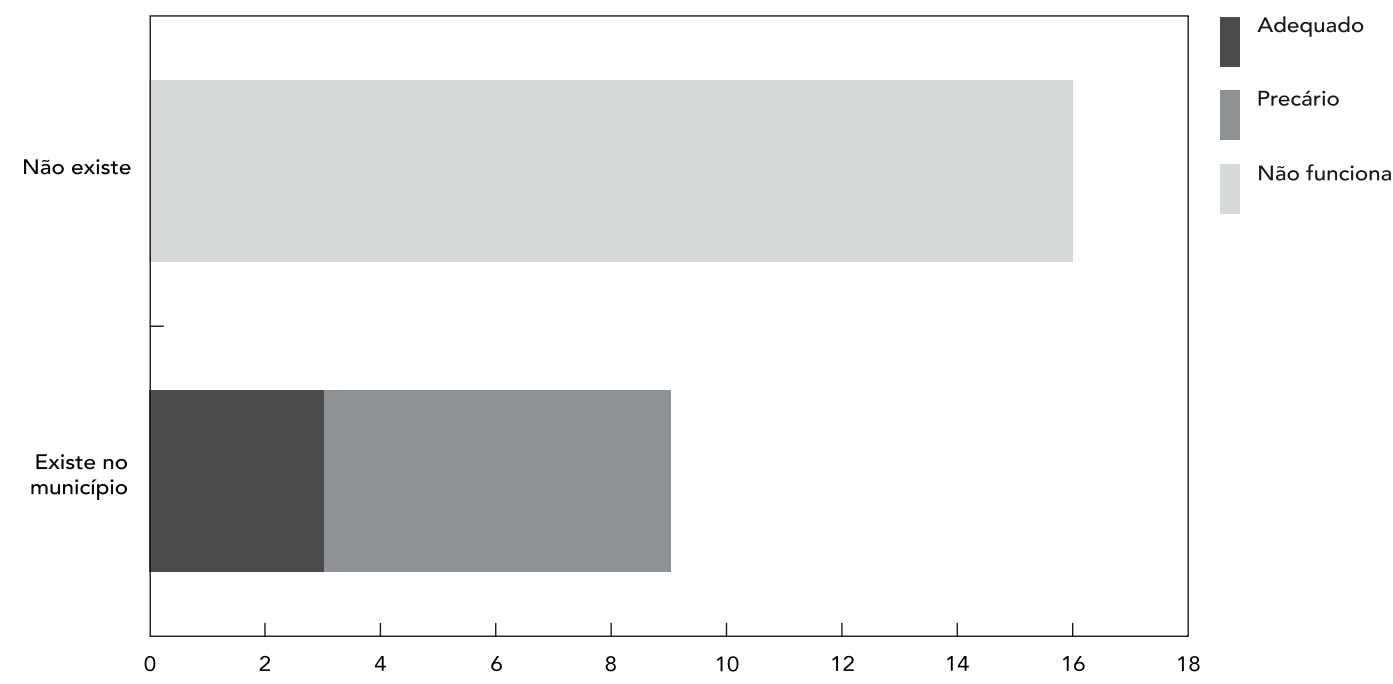


satisfatória têm uma pequena proporção da população em relação à população total da amostra. O município com maior proporção da população apresentou cobertura insatisfatória.

De um modo geral, portanto, observou-se, no presente estudo, que o modelo assistencial desenvolvido pela saúde bucal ainda tenta desatar os nós críticos do referenciamento para a atenção secundária e terciária. Considerando a importância de oferecer à população todos os níveis de complexidade do tratamento, incluídos no princípio da integralidade da atenção, verificou-se que a maioria dos municípios ainda não supre essa necessidade. Segundo os gestores, as principais dificuldades para que isso aconteça residem no fato de não haver profissionais capacitados e centros de referência em saúde bucal.

\section{Organização do trabalho}

A mudança do processo de trabalho parece ser um dos maiores desafios para a equipe de saúde da família e equipe de saúde bucal no PSF. Segundo Franco \& Merhy 13 o "Programa reconhece um dos pontos principais para a mudança da prática assistencial, que é o processo de trabalho. O modo de assistir as pessoas, a produção do cuidado, que requer vínculo, divisão de responsabilidades e resolutividade, está diretamente ligada à concepção de trabalho e à subjetividade de cada profissional e usuário".

Com relação à realização de reuniões para avaliação e planejamento das ações da equipe de saúde da família e ao desenvolvimento de ações articuladas entre a equipe de saúde bucal e a equipe de saúde da família, a maioria dos municípios foi classificada como satisfatória. Apesar de nosso instrumento não conseguir captar os microprocessos envolvidos no trabalho em equipe, nossos resultados apontam para um trabalho de caráter apenas multidisciplinar, em que o problema no campo da saúde é tratado sem que os profissionais estabeleçam entre si efetivas relações no campo técnico ou científico. Idealmente (e este é um dos pilares do PSF), deve ser buscada a interdisciplinaridade entendida como estrutural, havendo reciprocidade, enriquecimento mútuo, com tendência a uma horizontalização das relações 14 .

Os dentistas e os gestores também foram questionados no que se refere ao desenvolvimento de ações intersetoriais. Do total de 44 entrevistados, 40 (91\%) afirmam realizar ações que integrem a saúde bucal. As atividades intersetoriais mais citadas se referem às ações de educação e prevenção em saúde bucal desenvolvidas na comunidade ou nas escolas.
Diante disso, podemos fazer algumas considerações. A primeira é que muitos dentistas e gestores têm um entendimento equivocado sobre ação intersetorial, resumindo o seu significado ao desenvolvimento de mutirões ou participação em conferências, ou ainda a atividades preventivas na unidade. A segunda é que, apesar de a maioria dessas ações referirem uma parceria com a Secretaria de Educação para a prevenção e educação em saúde bucal, a efetivação na prática consiste em palestras e aplicações tópicas de flúor, o que não necessariamente precisaria ser feito nas escolas. Por último, essa ênfase nos escolares pode cair nas armadilhas da exclusão em virtude da priorização dessa população. Tal prática é, em certa medida, um resquício do modelo de atenção à saúde bucal em escolares, surgido ainda nos anos 1950 e representado principalmente pelo Sistema Incremental (sistema de atendimento de escolares de escolas públicas, na faixa etária de 7 a 14 anos, que, apesar de suas limitações, tinha uma estrutura organizacional muito forte e um sistema de atendimento bem normatizado).

\section{Estratégias de programação}

O cumprimento dos princípios do SUS, como a universalidade e eqüidade, requer das equipes de saúde bucal o conhecimento de sua realidade local, da sua comunidade adstrita. Daí a necessidade de organizar as ações valendo-se de estratégias de programação que utilizem critérios para a priorização da população mais necessitada. Quando os serviços conseguirem se apropriar dessa tecnologia e compartilharem com a comunidade suas prioridades, todos se beneficiarão, pondo-se em prática dois princípios do SUS, a eqüidade e o controle social 15.

Tão importantes quanto a realização de diagnósticos epidemiológicos são a utilização destes pelos profissionais e a continuidade na sua realização. Nesse sentido, foi interessante observar que apenas um município foi classificado como satisfatório por ter realizado um diagnóstico e por este ser usado pelos dentistas na ponta do serviço. A maioria dos municípios ou não realiza esses diagnósticos (insatisfatórios), ou, quando os realiza, eles não são instrumentos de trabalho dos dentistas.

Entretanto, é importante destacar que a proporção de municípios que realizaram diagnósticos epidemiológicos foi afetada pela própria metodologia do estudo, a qual incluiu na amostra os municípios participantes do levantamento epidemiológico realizado no Rio Grande do Norte, o Projeto SB Brasil-RN 10.

Foram citados os seguintes procedimentos realizados individualmente no consultório: exo- 
dontias, evidenciação de placa, orientação da dieta, aplicação tópica de flúor, restaurações, orientação de higiene oral e procedimentos básicos de periodontia. Destes, os três últimos foram os mais referidos.

A realização de palestras foi a atividade coletiva mais citada, seguida da aplicação tópica de flúor e da escovação supervisionada. O espaço mais destacado para o desenvolvimento dessas ações foi o das escolas, com $47,7 \%$ das citações, seguido das creches $(31,8 \%)$.

Mais uma vez encontramos resquícios da saúde do escolar, como discutimos anteriormente, quando observamos novamente a expressiva ação nas escolas dirigidas a seus alunos. Mas também cabe aqui uma outra discussão. As ações coletivas descritas giram em torno das palestras tradicionais, das aplicações tópicas de flúor e da escovação supervisionada, que parecem ser incorporadas à prática sem critérios e sem controle de sua eficácia.

Chaves \& Vieira-da-Silva 16 realizaram uma revisão sistemática de vários estudos experimentais que tinham como objetivo avaliar a efetividade de medidas preventivas no controle da cárie dental. As práticas preventivas mais avaliadas foram os dentifrícios, os bochechos com flúor e os selantes oclusais. Chegaram à conclusão de que a educação em saúde bucal, como ferramenta básica para qualquer ação preventiva específica, está sendo pouco considerada nos estudos de intervenção isolados. Além disso, constataram uma grande heterogeneidade nos resultados encontrados, o que pode ter sido conseqüência, dentre outros fatores, de onde, de como e de quem implementa as medidas preventivas, ou seja, estão diretamente ligados ao contexto histórico, cultural, social e organizacional do local onde as medidas são implementadas.

Dessa forma, mais importante do que desenvolver ações coletivas de prevenção e educação em saúde bucal é realizá-las racionalmente, com avaliações periódicas para saber se realmente estão sendo efetivas, e não simplesmente instituir um "pacote preventivo", o qual tem sido implementado acriticamente pela maioria das equipes de saúde bucal.

A avaliação das ações em saúde bucal é realizada por $84,2 \%$ dos gestores; destes, grande parte utiliza o pacto da atenção básica para este fim. A maioria dos dentistas $(72 \%)$ nunca realizou avaliação.

Diante disso, é possível fazer algumas considerações. Inicialmente, fica claro que as avaliações das ações são realizadas principalmente pelos gestores, ou seja, ainda está muito restrita aos setores administrativos dos municípios, o que não seria problemático se a gerência com- partilhasse suas análises, resultados e possibilidades de mudanças com os profissionais que trabalham na ponta do serviço. Em segundo lugar, as fontes utilizadas para avaliação, tanto pelos gestores, como pelos dentistas, parecem frágeis e precárias. Mesmo que o pacto da atenção básica tenha sido o mais citado como instrumento, não significa dizer que está havendo uma avaliação criteriosa por parte dos municípios que o utilizam, até pelas conhecidas limitações dos sistemas de informação, como os poucos indicadores específicos para a saúde bucal e os muitas vezes incorretos registros de informação por parte dos municípios. Além disso, não há indicadores disponíveis para a saúde bucal no Sistema de Informação da Atenção Básica (SIAB), com exceção dos procedimentos coletivos.

Conill 17, em seu estudo, chegou à conclusão de que a gerência, o controle e o acompanhamento do PSF parecem ser ainda precários. Ainda que a implantação do SIAB seja vista por alguns com otimismo, para outros, a estratégia expansionista, apesar de positiva por difundir os princípios da integralidade, quando não associada a um acompanhamento, traz alguns perigos para o desempenho do programa.

\section{A pesquisa documental}

Os documentos encontrados relativos às informações em saúde bucal foram categorizados em quatro tipos: relatórios, projetos ou programas, documentos de registro (fichas clínicas e fichas utilizadas pelos agentes comunitários de saúde nas visitas) e protocolos de atendimento. Apenas 11 municípios forneceram algum tipo de documento, e três destes forneceram apenas a ficha clínica, o que dificultou a análise. Isso, de certa forma, aponta para uma deficiência técnica e organizacional dos serviços em saúde bucal, ou, até mesmo, para o fato de os gestores e dentistas não terem despertado para importância de elaborar, avaliar e registrar as ações desenvolvidas.

Com exceção dos protocolos de atendimento, que foram desenvolvidos pelos dentistas juntamente com a coordenação de saúde bucal, percebe-se que os programas são elaborados e desenvolvidos unicamente pelos dentistas, da mesma forma que a realização das ações não dispõe de maior suporte técnico, administrativo e financeiro. Este é, provavelmente, um ponto negativo, pois condiciona a existência das ações e dos programas à permanência do profissional no município e, principalmente, ao estímulo que ele tenha para desenvolvê-las. Não se trata, portanto, de propostas institucionalizadas e integradas ao sistema de saúde dos municípios, mas de iniciativas pessoais e isoladas. 
Em síntese, foi possível perceber que alguns municípios já estão tentando registrar suas ações e suas programações em saúde bucal, ainda que de forma incipiente, oriunda da iniciativa isolada dos atores (profissionais e gestores) envolvidos no processo de mudança do modelo assistencial. Esse registro é considerado muito válido se pensarmos que, há poucos anos, provavelmente pouquíssimos municípios demonstravam essa preocupação. O importante agora é estimular essa discussão, a fim de proporcionar maiores condições de se desenvolverem projetos e ações institucionalizados, baseados em critérios objetivos e nas necessidades da população.

\section{Aspectos da observação estruturada}

Com o objetivo de caracterizar as tecnologias utilizadas pela saúde bucal no PSF, importantes na organização do trabalho, todas as unidades de saúde da família que tiveram cirurgiões-dentistas entrevistados no nosso estudo foram visitadas e observadas, totalizando 25 unidades. Observouse a unidade como um todo, com maior atenção à sala do consultório odontológico e aos espaços nos quais a equipe de saúde bucal pudesse desenvolver ações, existentes ou não.

Oito unidades de saúde da família visitadas foram classificadas como insatisfatórias para o atendimento à população usuária do serviço de saúde. Todas apresentaram problemas físicos, como falta de sala de espera ou sala de espera pequena e suja, além de salas destinadas ao atendimento odontológico em condições precárias. Um ponto em comum entre essas unidades, com exceção de uma delas, foi o não-atendimento durante a observação por falta de material de consumo (luvas, amálgama ou anestésicos), pela falta de limpeza ou por estar passando por reformas. Além disso, observou-se a falta de instrumental clínico em várias delas.

Mesmo não apresentando grandes problemas com relação às "tecnologias duras" 18 necessárias ao atendimento odontológico, as unidades classificadas como pouco satisfatórias apresentaram problema estruturais, como pouco espaço físico ou paredes deterioradas. Diferentemente das unidades consideradas insatisfatórias, mais da metade das unidades consideradas pouco satisfatórias possui um espaço destinado ao desenvolvimento de atividades educativas.

Apenas duas unidades foram classificadas como adequadas com relação à estrutura de atendimento à população. Além de contarem com salas odontológicas bem equipadas, a estrutura física das unidades encontrava-se excelente.

Com exceção das unidades dos municípios considerados insatisfatórios, de modo geral, as unidades de saúde da família observadas, embora precisem de algumas melhorias, conseguem oferecer o tratamento curativo aos usuários, ainda que não utilizem instrumentos e equipamentos novos. Por outro lado, fica evidente que o modelo centrado em "tecnologias duras", historicamente determinado, ainda encontra dificuldades para oferecer à população o uso de "tecnologia leves" 18 na organização do trabalho em saúde.

\section{Considerações finais}

Grande parte dos municípios não avançou no modelo assistencial em saúde bucal após a sua incorporação no PSF. Do total de 19 municípios, nove foram classificados como insatisfatórios nas mudanças apresentadas. Apenas cinco municípios apresentaram um perfil satisfatório e, nestes, já observamos avanços mais significativos, principalmente com relação à questão da intersetorialidade.

Pudemos observar, através da matriz avaliativa, os pontos mais críticos nos municípios, onde não se constataram, ainda, avanços nas relações de trabalho, no referenciamento dos pacientes para ações de média e alta complexidade, no desenvolvimento de ações intersetoriais, nas estratégias de programação (diagnóstico epidemiológico e avaliação das ações) e na infra-estrutura observada. Não se constataram também documentos importantes, como protocolos de atendimento e relatórios de ações desenvolvidas.

Os municípios classificados com um perfil insatisfatório ou pouco satisfatório apresentam IDH-M baixo ou médio e encontram-se distribuídos em todas as unidades regionais de saúde pública do Rio Grande do Norte, com exceção da unidade regional de saúde pública da Grande Natal. Esses municípios possuem algumas características semelhantes: apresentam altas taxas de mortalidade infantil e baixa esperança de vida ao nascer. A maioria deles revela um percentual de crianças analfabetas, na faixa etária de 7-14 anos, maior do que a média do Estado, além de ter maiores desigualdades sociais. Na sua maioria, a renda per capita é baixa e há altas intensidades de pobreza e indigência 19 .

Os cinco municípios classificados em condição de avanço do modelo assistencial, portanto com um perfil satisfatório, são todos os que têm IDH-M alto, distribuindo-se em quatro unidades regionais de saúde pública do Estado. Com exceção de um deles, que conta com aproximadamente 26 mil habitantes, todos têm população acima de 50 mil habitantes. Caracterizando esses municípios de acordo com outras variáveis, 
podemos perceber que eles apresentam baixas taxas de mortalidade infantil, revelando, inclusive, as menores taxas do Rio Grande do Norte, as melhores taxas de esperança de vida ao nascer, baixos percentuais de crianças na faixa etária de 7-14 anos analfabetas e os maiores percentuais de alfabetização da população. Apresentam, ain$\mathrm{da}$, renda per capita entre as maiores do estado e as menores intensidades de indigência e de pobreza 19 .

Nossa intenção ao correlacionar nossos resultados com outras variáveis, que são indicadores importantes das políticas públicas, foi demonstrar que, apesar de as políticas de saúde oferecerem assistência à população, elas têm efeito limitado. Entendemos que a organização

\section{Resumo}

O objetivo deste estudo foi avaliar a incorporação da saúde bucal no Programa Saúde da Família no Rio Grande do Norte, com base na análise de fatores capazes de interferir no processo de mudança dos modelos assistenciais em saúde bucal. Esta avaliação tomou como referência três dimensões: o acesso, a organização do trabalho e as estratégias de programação. Foram sorteados 19 municípios no estado. Os instrumentos de coleta foram a entrevista estruturada aplicada a gestores e dentistas, a observação estruturada e a pesquisa documental. Foi possivel identificar precariedade nas relações de trabalho e dificuldades no referenciamento para média e alta complexidade, na intersetorialidade, no diagnóstico epidemiológico e na avaliação das ações. A maioria dos municípios apresentou pouco ou nenhum avanço no modelo assistencial em saúde bucal. Os municípios que demonstraram avanços apresentaram alta expectativa de vida ao nascer, baixas taxas de mortalidade infantil, valores per capita entre os mais altos do Estado e altos valores de IDH-M. Concluiu-se que políticas públicas que contemplam aspectos além dos pertinentes ao setor saúde são decisivas para uma real mudança nos modelos assistenciais.

Saúde Bucal; Programa Saúde da Família; Serviços de Saúde de boas políticas de saúde está vinculada a outras políticas, como de educação, emprego, renda e moradia, tendo em conta o conceito ampliado de saúde. Portanto, é esperado que, nos municípios onde haja um conjunto de políticas públicas mais definido e melhores condições sócio-econômicas, também exista um modelo de atenção à saúde bem estruturado.

Nesse sentido, podemos perceber que os municípios que mais avançaram são aqueles que apresentam melhores condições de vida da população, o que pode ser reflexo de políticas públicas, dentre elas as de saúde, menos excludentes e mais integradas. Ademais, refletem as limitações acerca do entendimento da saúde apenas como oferta de serviços.

\section{Colaboradores}

T. M. S. Souza realizou a revisão de literatura, a coleta de dados e sua análise. A. G. Roncalli colaborou de maneira fundamental para a realização deste trabalho, desde a revisão de literatura e definição da metodologia à análise e interpretação dos dados. 


\section{Referências}

1. Souza DS, Cury JA, Caminha JAN, Ferreira MA, Tomita NE, Narvai PC, et al. A Inserção da saúde bucal no Programa de Saúde da Família. Rev Bras Odontol 2001; 2:7-29.

2. Trad LAB, Bastos ACS. O impacto sócio-cultural do Programa Saúde da Família (PSF): uma proposta de avaliação. Cad Saúde Pública 1998; 14:429-35.

3. Viana ALD, Dal Poz MR. A reforma do sistema de saúde no Brasil e o Programa de Saúde da Família. Physis (Rio J) 1998; 8:11-48.

4. Brasil. Portaria n ${ }^{\circ}$. 1.444, 28 de dezembro de 2000. Estabelece incentivo financeiro para reorganização da saúde bucal prestada nos municípios por meio do Programa Saúde da Família. Diário Oficial da União 2000; 29 dez.

5. Calado GS. A inserção da equipe de saúde bucal no Programa de Saúde da Família: principais avanços e desafios [Dissertação de Mestrado]. Rio de Janeiro: Escola Nacional de Saúde Pública, Fundação Oswaldo Cruz; 2002.

6. Coordenação de Saúde Bucal, Departamento de Atenção Básica, Secretaria de Atenção à Saúde, Ministério da Saúde. Diretrizes da Política Nacional de Saúde Bucal. Brasília: Ministério da Saúde; 2004.

7. Zanetti CHG. Opinião: a inclusão da saúde bucal no PACS/PSF e as novas possibilidades de avanços no SUS. http://www.saudebucalcoletiva.unb.br (acessado em Jun/2003).

8. Moysés SJ, Silveira Filho AD. Saúde bucal da família: quando o corpo ganha uma boca. In: Silveira Filho AD, Ducci L, Simão MG, Gevaerd SP, organizadores. Os dizeres da boca em Curitiba: boca maldita, boqueirão, bocas saudáveis. Rio de Janeiro: Centro Brasileiro de Estudos da Saúde; 2002. p 133-61.

9. Carvalho CL, Girardi SB. Agentes institucionais e modalidades de contratação de pessoal no Programa Saúde da Família no Brasil. Belo Horizonte: Núcleo de Pesquisa em Saúde Coletiva, Universidade Federal de Minas Gerais; 2002.

10. Secretaria de Estado de Saúde Pública. Levantamento epidemiológico em saúde bucal no Estado do Rio Grande do Norte. Projeto SB Brasil-RN. Natal: Secretaria de Estado de Saúde; 2003.
11. Pine C, Pitts NB, Nugent ZJ. British Association for the Study of Community Dentistry (BASCD) guidance on sampling for surveys of child dental health. A BASCD coordinated dental epidemiology programme quality standard. Community Dent Health 1997; 14 Suppl 1:10-7.

12. Departamento de Atenção Básica, Secretaria de Políticas de Saúde, Ministério da Saúde. Monitoramento da implantação e funcionamento das equipes de saúde da família no Brasil. Brasília: Ministério da Saúde; 2002.

13. Franco T, Merhy E. PSF: contradições e novos desafios. http://www.datasus.gov.br/cns/cns.htm (acessado em Abr/2003).

14. Almeida Filho N. Transdisciplinaridade e saúde coletiva. Ciênc Saúde Coletiva 1997; 2:5-19.

15. Silveira Filho AD. A saúde bucal no PSF: o desafio de mudar a prática. http://www.saudebucalnobrasil.cjb.net (acessado em Mai/2003).

16. Chaves SC, Vieira-da-Silva LM. As práticas preventivas no controle da cárie dental: uma síntese de pesquisas. Cad Saúde Pública 2002; 18:129-39.

17. Conill EM. Políticas de atenção primária e reformas sanitárias: discutindo a avaliação a partir da análise do Programa Saúde da Família em Florianópolis, Santa Catarina, Brasil, 1994-2000. Cad Saúde Pública 2002; 18 Suppl:191-202.

18. Merhy E, Chakkour M, Stéfano E, Stéfano ME, Santos $\mathrm{CM}$, Rodrigues RA, et al. Em busca de ferramentas analisadoras das tecnologias em saúde: a informação e o dia-a-dia de um serviço, interrogando e gerindo trabalho em saúde. In: Merhy E, Onocko R, organizadores. Agir em saúde: um desafio para o público. São Paulo: Editora Hucitec/Buenos Aires: Lugar Editorial; 1997. p. 113-50.

19. Programa das Nações Unidas para o Desenvolvimento. Atlas de Desenvolvimento Humano. http://www.pnud.org.br (acessado em Mar/2004).

Recebido em 29/Mar/2006

Versão final reapresentada em 10/Mar/2007

Aprovado em 07/Mai/2007 